July 20, 1848 , and describes how parts of the coast suddenly appeared, standing, so to speak, in the middle of the channel.

Coming to recent times, we have a description in the Zagara for $\mathrm{I} 87 \mathrm{I}$ by an anonymous writer. A white streak of mist passing across the Sicilian coast melted like a transparent veil, revealing arches, towers and colonnades floating on the sea, houses, and woods of many colours.

Not less explicit is Prof. Filippo Capri, who described in the Zagàra the Fata Morgana of June 20, 1874 , which occurred between 8 and 9 a.m. The weather was so hot as to ruin the crop of bergamot fruit, and the phenomenon, as on other occasions, was preceded by a white mist. Buildings were seen to become elongated, while the shores, with their villas and trees, became detached like islands and then disappeared. In answer to the invitation for an explanation, Dr. Diego Corsa repeated Minasi's erroneous opinions, but this point of view was attacked by Prof. Canale, who, however, did not venture to formulate a theory of his own, having only seen the phenomenon once.

Prof. Boccara speaks from personal knowledge of three displays of the Fata Morgana under its three different

FIG. I.

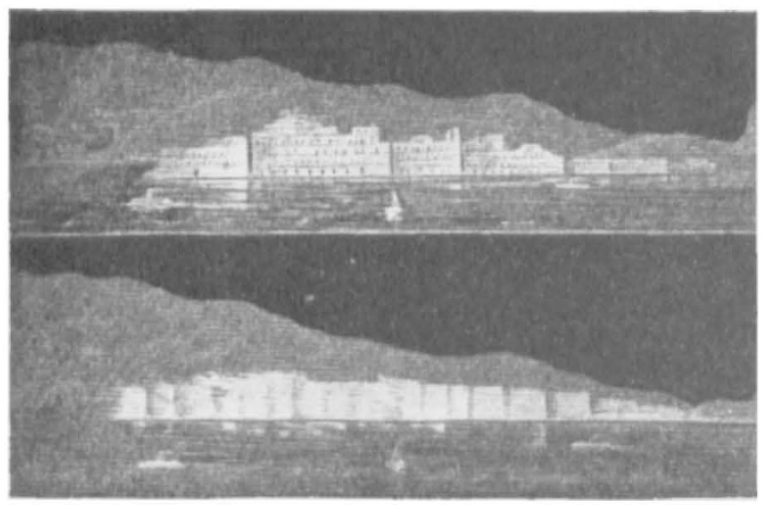

FIG, 2.

Fig. r.-Aërial Morgana of June 27, rgoo.

FIG. I.-Aërial Morgana of June 27, r9oo.
FIG. 2 shows the white mist just before the commencement of the phenomenon.

forms-namely, an aërial morgana on June 27 , I900, witnessed by himself, Captain Vincenzo Ponzi, of Chiaggia, and Prof. Enrico Puccini ; a marine morgana on July 2, 190I, also seen by Prof. Puccini ; and a multiple morgana on March 26, I902. The first is well shown by the author's sketch in Fig. I, Fig. 2 giving an idea of the white mist seen just before the occurrence of the phenomenon, and which disappeared when the occurrence took place. In it, the houses on the Italian coast at Gallico and the point of Catona are seen to be considerably elongated in a vertical direction, and, so to speak, projected on the Sicilian coast beyond, the straits appearing to be converted into a gulf. In the marine morgana of I90I, a cloud again formed just previously, and the appearance was presented of arches standing below the sea line in an upright position, their bases having no visible foundation. These arches corresponded to some railway arches above the cemetery of Messina, but were more brilliant and larger than the real arches. Of the third or multiple morgana, Prof. Boccara has given an illustration in Fig. 3, which, however, represents simultaneously various phases of the phenomena which were in reality seen in succession. Thus the three houses at the left were not all visible at the same instant; when one appeared, the other disappeared. The white band with vertical dark stripes was attributed to the wall of the citadel at Messina, and it appeared to blot out the houses of the town.

Prof. Boccara attributes all these phenomena to variations in atmospheric density, which produce refraction effects. It may be suggested to the mathematician that consideration of the principle of least time for the path of a light ray affords an easier way of thinking of the conditions necessary for the phenomenon than is given by the sine law of refraction. The term Fata Morgana is used by the author exclusively in connection with apparitions in which the images are erect. When inversion takes place, so that the phenomena are due to reflection, the effect is a mirage, a phenomenon also seen not unfrequently on the Sicilian coast.

The neighbourhood of Reggio is peculiarly adapted to the display of the Fata Morgana both by its topographical peculiarities and by the meteorological conditions not unfrequently existing there These conditions are, a morning hour, hot weather, extreme clearness of the air, combined, however, with a thin veil of mist over the Sicilian coast, and a calm air or slight wind from the north, as conditions for the marine morgana. For the aërial morgana, the best time of day is from ro a.m. to I p.m., with a stratum of light cloud on the coast of Sicily, sea calm or nearly so, a high temperature and

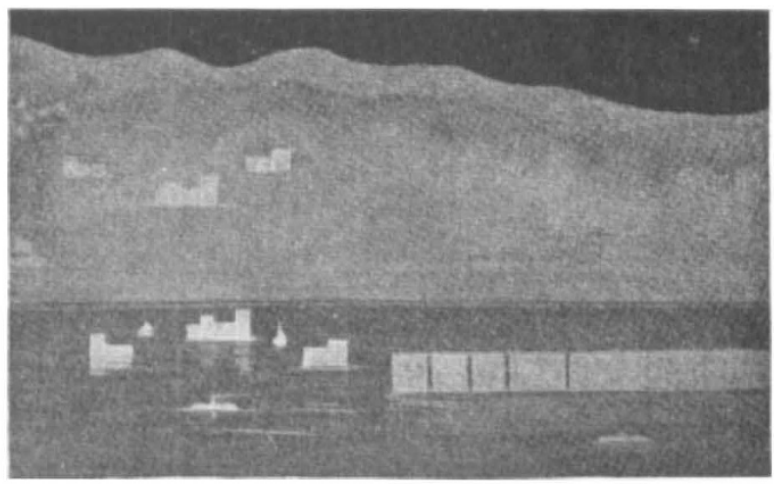

FiG. 3.-Multiple Morganã of March 26, 1902

wind as before. A multiple morgana is, or course, of much rarer occurrence than the simple form, and the one seen in March, 1902, was less marked than one observed about twenty years previously by Prof. Scerbo and Signor Aloi, of which a sketch is reproduced in Dr. Boccara's paper.

G. H. B.

\section{INDIAN RAINFALL}

F VERYONE acquainted with the rainfall statistics of India is familiar with the appendix to the third volume of the Indian Meteorological Memoirs, which was published in the year I888, when Mr. H. T. Blanford was Meteorological Reporter to the Indian Government. This appendix contained the monthly and yearly rainfalls for each station which possessed a rain-gauge, and the period over which the observations extended was in some cases, such as Bombay, Madras and Calcutta, very long, the last year in which the observations from all stations were included being that of 1886 .

Since that epoch many years have passed, and the time had evidently arrived for this volume to be brought up to date and the whole mass of useful rainfall data collected together under one cover. We are glad to say that this large piece of work has now been completed and published (1902), and forms the fourteenth volume of the Memoirs. 
Under the able editorship of the present Meteorological Reporter and Director-General of Indian Observatories, Sir John Eliot, this new volume contains all the available data up to, and including, the year 1900 , and it is to this volume that inquirers of Indian rainfall statistics will now turn. Several minor changes will be found to have been made in the tables, such as zero (o) instead of $(.$.$) when no$ rain had fallen during a month, the authorised orthography, \&c., but the most valuable addition is undoubtedly the insertion of two extra columns for each station giving the total rainfall for each monsoon.

India, as most people know, receives its rain mainly at two periods of the year, namely, during the summer months when the south-west monsoon is blowing, and during the winter months when the north-east monsoon is blowing. In any investigations on the variation of rainfall due to extra-terrestrial origins or involving atmospheric circulation, it is of the greatest importance to be able to treat the monsoon rainfalls separately. Again, some stations are more favourably placed, geographically, to depend chiefly for their yearly rainfall on one or other of the monsoons, or both; thus Bombay's rainfall is entirely due to the south-west monsoon, while the wind which gives Madras its rain is the north-east; further south, in southern India, several of the places are more fortunate, and secure their rains from each monsoon in turn, so that if one monsoon fails them, they still have a chance of obtaining their rain from the other.

In dealing with such a large area of country as is covered by the Indian Meteorological Department, it was found desirable to adopt a grouping of the months for each monsoon that would be general to the whole of India, with the least detriment to some individual areas.

Thus the months finally settled upon were as follows :-N.E. monsoon, December to April; S.W. monsoon, May to November. The two columns, therefore, that are inserted for the first time in this volume show the total rainfall at stations during the five months ending April 30 of the year in question, and the total rainfall of the seven months ending November 30 of that year.

The fact that this volume contains no less than 709 pages and weighs $5 \mathrm{lb}$. $x_{4} \frac{2}{2} \mathrm{Oz}$. in its paper cover, will give the reader some idea of the mass of rainfall statistics it contains and of the labour involved in bringing the information together. The volume should serve as an admirable model for other countries to adopt, and it would be to the advantage, not only of Great Britain and her Colonies, but also of many foreign countries in various parts of the world, to coordinate their rainfall observations in a similar manner, so that such records, which are well worth making, are ready at the hand of any investigator who at the time may be working up the subject.

William J. S. LOCKYeR.

\section{THE AFFORESTATION OF THE BLACK COUNTRY.}

$\mathrm{N}$ the spring of 1892 , when marking trees for cutting 1 in the Belgian Ardennes (Chateau de Mirwart), I noticed that a portion of the wood, alongside a meadow and a watercourse, had the irregular shape of spoil heaps. On inquiry, I found that some 200 years before iron-smelting had been carried on at the spot, and that the heaps consisted of old slag and other débris, such as may be expected under a rudimentary process of iron-smelting. The heaps were stocked with oak and ash trees, some of them of considerable size and vaiue, others of smaller dimensions. I marked the large trees for sale, leaving all middle-sized and smaller trees. The latter girthed up to 4 feet at 5 feet from the ground, while the trees marked for cutting girthed 6 feet, and even more. I considered this a very interesting case, but as I did, at that time, not know the Black Country, it did not strike me to utilise my experience for the benefit of the English mining districts.

Towards the end of the same year, Mr. W. R. Fisher visited me at Mirwart, and when he saw the above mentioned case, it struck him to apply it to the Black Country. He subsequently visited that locality and urged its afforestation on more than one occasion. The honour of having brought the subject prominently before the public belongs to Mr. Fisher.

I have just read an account of a meeting at Birmingham, presided over by Sir Oliver Lodge, to inaugurate a society for promoting the afforestation of the Black Country. As the result of the meeting, a resolution was carried, a committee was formed, and Mr. Herbert Stone was elected hon. secretary of "The Black Country Tree-planting Society."

The area in question is believed to be 14,000 acres, covered with spoil and ash heaps, on which now some grass grows; it is grazed over by sheep. Sir Oliver Lodge, quite correctly, brought the probable financial results of afforestation into the foreground, while some of the other speakers referred to the importance of a sylvan environment for moral, hygienic, and æsthetic considerations, leaving the financial aspect to take care of itself. This I consider a mistake, because, with the best intentions, humanitarian considerations alone are not likely to achieve the object in view; besides, they can very well be realised, alongside of good financial results.

The area in question belongs, I understand, to a number of different proprietors, and this alone would probably be a great hindrance to bringing the undertaking to a successful issue. In my opinion, the adjoining municipalities, such as Birmingham, Dudley, Bilston, Wolverhampton, Darlaston, Wednesbury, Oldbury, \&c., should put their heads together, devise a plan of acquiring the land in question, which cannot be of much value, and create a joint municipal forest estate, to be managed by one man. This manager might be made responsible to a joint committee, and under its orders carry out the afforestation of the area on a well-considered plan. In that case, æsthetic considerations can receive full attention, while the woods should be so laid out, as to species, \&c., that a reasonable return on the outlay may be expected.

If the plan here sketched should prove to be impracticable, it would be quite worth while for the State to acquire the land and plant it up. In any case, a well-considered plan of action as regards the manner of afforestation, the species to be planted, \&c., is a sine qua non of ultimate success, and the drawing up of such a plan should be entrusted to an expert, who is fully conversant with the management, and more especially the financial management, of forest estates. I lay stress on this, because I see it stated that sycamore, ash, lime, beech and poplar should be planted. There will, no doubt, be many places where these trees can be introduced, but the bulk of the area should be stocked with fast-growing conifers, the thinnings of which will, at an early age, give large quantities of pit timber, and thus secure favourable financial results. W. Schlich. No. 1739 , vOL. 67] 